\title{
Vattenwebb: A Transparent Service to Support Decision Makers in Achieving Improved Water Status
}

\author{
Lena Strömbäck, Niclas Hjerdt, Lena Eriksson Bram, and Per Lewau \\ Swedish Meteorological and Hydrological Institute, \\ Folkborgsvägen 1, 60176 Norrköping, Sweden \\ lena.stromback@smhi.se
}

\begin{abstract}
The vattenwebb.smhi.se service provides simulated as well as measured data on water flow and water quality for Sweden. The available data is used by the water authorities and decision makers in Sweden. The development of the site has been driven by the needs of the users and resulting in a site that is very appreciated by its users. An important aim in the development has been to make the data transparent for the end users, i.e. to explain the model assumptions and data quality in a way that is easy accessible. Therefore the site contains explanations about the model setup, how this data has been computed and information about the performance of the model. In this paper we will describe the service and its features with an emphasis on features used for achieving transparency.
\end{abstract}

Keywords: Hydrology, HYPE, environmental modeling, water management.

\section{Introduction}

Water management in Sweden is focused on characterization of water bodies and establishing action plans to achieve a good ecological status according to the framework directives stated by the European Union. To support this work SMHI has been commissioned to make databases of hydrography, statistics, water flows and scenario models freely available on the web. As a result of this we have created the open website vattenweb.smhi.se making collected and simulated information regarding discharge and nutrient load available for the end users. However, important when users are assessing this data is that they understand the viability, assumptions and uncertainties within the modeled results. Therefore, the development of the site has been done in close cooperation with the end users. This has resulted in a transparent web site that exposes information on the model setup and result evaluations for the end user to enable them to assess the validity of the presented values.

The aim of the website [1] is to provide historical data about water quantity and quality in Sweden. These data will provide an important basis for assessing water quality and establishing action plans in Sweden. On the site simulated data on fresh water quantity and quality are provided by the S-HYPE model [2], [3], a Swedish setup of the Open Source HYPE model [4], [5]. The model provides historical simulations of daily values for discharge and monthly values for transport of nitrogen 
and phosphorous for the sub basins defined in the Swedish Water ARchive (SVAR [6]). Currently, the site provides observed and modeled data for fresh water and coastal areas as time series and statistics. In addition to this, the site also exposes data on wetlands and results from climate scenario simulations.

There are many challenges with developing and making this kind of dataset available to decision makers and to the general public. One such challenge is, of course, the development of the S-HYPE simulation model to provide an as good dataset as possible. Another, as important, challenge is to make this data available in a format that makes it useful for the decision makers. This includes usability issues, but also to make the simulation model transparent, enabling decision makers to understand assumptions and uncertainties within the model and use the data in a correct way.

In the paper we will give a general overview of the design and features of the web site and the data it provides. We will start with giving a general overview of the provided functionality on the web site, including a short introduction to the hydrological simulation model S-Hype. We will then describe the design process and user involvement in the development of the design, and describe the main design principles this has led to. After this we focus on the issue of transparency and describe how this has been achieved by making more information about the S-hype model available for the end users on the site.


Fig. 1. This figure gives an overview of vattenwebb.smhi.se. The start page where each blue square represents one application is shown in the top left part of the figure. To the right we show the map view used for selecting an area of interest. The bottom right part of the figure shows the view used for downloading input data and statistics for the whole Sweden. 


\section{An Overview of the Service}

As explained above the vattenweb.smhi.se service provides measured and simulated data for rivers and the coast of Sweden. Figure 1 shows the front page of vattenweb.smhi.se service where the different services are available as applications or apps for the end users. Each of the apps is shown as a blue box on the front page. The top line of applications is used to download data. The leftmost application gives the user the ability to select a sub basin of his interest and then download simulated data for this area. The data available includes historical time series for discharge and water quality, statistics and model input for the selected basin. The middle app gives similar information represented as summaries for the whole Sweden. The rightmost application gives the ability for the user to download observed values. The second line of application provides interactive evaluation tools that shows how well the models perform compared to the observed values. The applications of the bottom line concerns wetlands and climate predictions and will not be further discussed in this paper. In addition to data the web site contains a reference guide explaining details about the model setup.

In this paper we focus on fresh water and water quality modeling applications of the site. The simulated data for fresh water and water quality is provided by hydrological simulation model HYPE (Hydrological Predictions for the Environment) [4], [5] for modeling the hydrological processes in an area. The HYPE model simulates water flow and substances on their way from precipitation through soil, river and lakes to the river outlet. It is developed for being easy to set up for large scale applications and to make use of existing data about geography. The geographic area to be modeled consists of one or several catchment areas each catchment is divided into subbasins which are the basic unit for describing the hydrological processes. The HYPE model is developed for being easy to set up for large scale applications and to make use of existing data about geography where such are available.

For S-HYPE 2012, which is the HYPE model for Sweden currently used in vattenweb.smhi.se, the model setup consist of around 37000 subbasins derived from the SVAR [6] database. For each subbasin different properties relevant for water and water quality is described. This includes how the land is used i.e. whether it is covered by e.g. forest, lake, or open land. For agricultural land we describe which crops are most common and how these are fertilized. Elevation is used to describe temperature variations within a subbasin to influence the snow conditions. To be able to model water quality it is also important to describe emissions from different sources and their content of phosphorus and nitrogen. To describe nutrient transformation the soil is modeled as several layers different for each land use. As an example agricultural land classes commonly use three soil layers. Table 1 gives an overview of data sources for the S-HYPE 2012 model setup, while more details is available in our reference guide [1]. The final model setup is calibrated and evaluated against observations for a high number of gauging stations, for most of these the observed data is available on the website. 
Table 1. Facts about the S-HYPE 2012 model setup.

\begin{tabular}{|l|l|}
\hline $\begin{array}{l}\text { Modeled geographic } \\
\text { area: }\end{array}$ & Sweden \\
\hline Total area (km $)$ : & 525000 \\
\hline No. of sub-basins: & $\sim 37000$ \\
\hline No. of discharge stations: & 303 \\
\hline Topography: & SVAR (SMHI) \\
\hline Land Use: & $\begin{array}{l}\text { CORINE updated with information from SVAR for lakes } \\
\text { and SJV (Board of agriculture) for agricultural land }\end{array}$ \\
\hline Soil: & SGU (Geological Survey of Sweden) \\
\hline Discharge observations: & SMHI \\
\hline Precipitation: & PTHBV (SMHI) \\
\hline Temperature: & PTHBV (SMHI) \\
\hline Lakes and reservoirs: & SVAR (SMHI) \\
\hline Point sources: & FUT environmental monitoring (SMED) \\
\hline Crop types: & SCB (Statistics Sweden) \\
\hline
\end{tabular}

\section{User Involvement and Main Design Principles}

The main users of the site are the Swedish water authorities and municipalities that need this data as background for decisions and reports. Therefore, the development of the site has been done in close cooperation with the end users at the water authorities to meet their needs and requirements. The users have been active in the design of the site and are involved in all steps of the development of new features. In practice, users are welcome to suggest new data and new features. These features are discussed and prioritized together with the existing development plan in a selected group consisting of SMHI officials and representatives for the users in the water authorities. Moreover, users take part in the development phase of the new features as participants in reference and expert groups.

This process has been very important for the design of the site. As expected, large parts of the discussions with end users focus on exactly which data to publish, what it represents and how it is computed. However, during this process it became obvious that an as important issue for the end users is to understand the S-Hype simulation model and its underlying encoded assumptions in order to assess how to use the results in relation to a specific task. There were also many questions regarding quality of the results. This process has resulted in a web site where we have adopted four main design principles for the site. These principles are further described below: 


\subsection{Data Is Available in the Way the User Needs Them}

One of the most important properties of the site is that data is available as desired, in a way that makes it easy to select interesting data. Therefore the basic design is focused around the first page presenting a selection of available data as different applications. As one example, for download of data we have two options where the user can decide whether he is interested in data for a particular geographic area or general information for the whole country. For each of these choices it is easy to select data by clicking in the map or choosing dataset for Sweden. Figure 1 gives an overview of these selections on the site, while figure 2 shows one area selected for download of data.

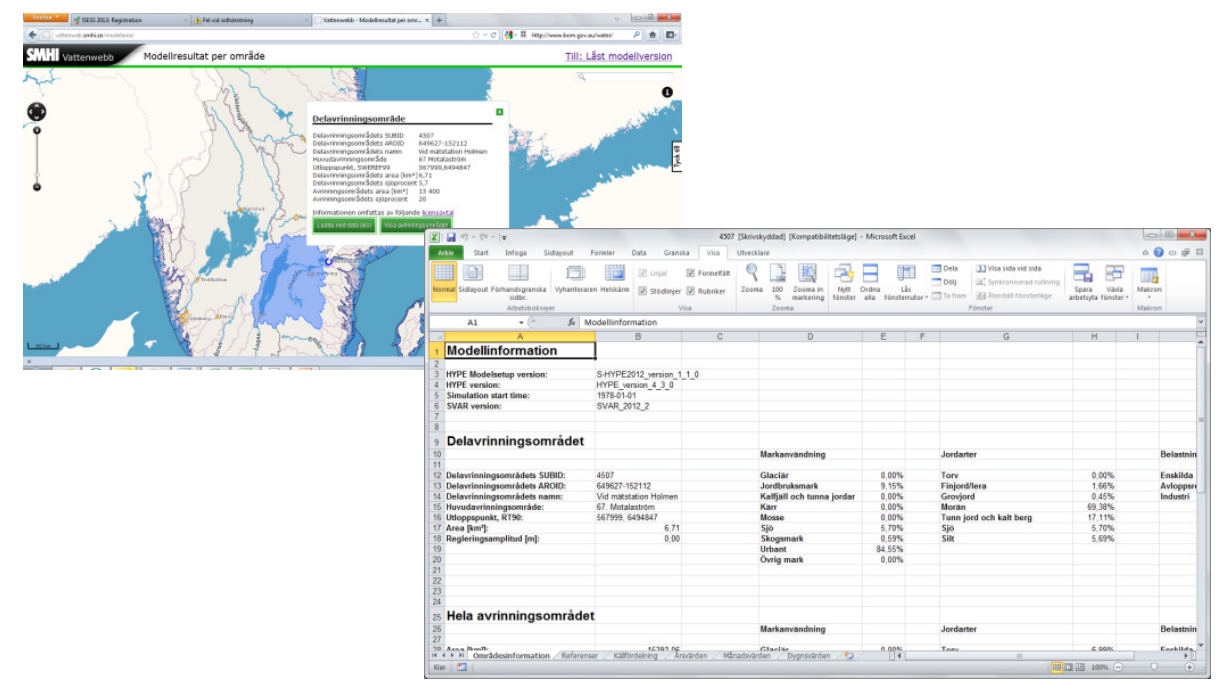

Fig. 2. At the top of this figure we show the map view with one specific area selected. To the bottom we show the Excel file resulting in downloading data for this area. The view show parts of the provided input data for the model, however, the file also contains statistics and time series for discharge and nutrients, source appointment, natural discharge and information about background and anthropogenic nutrient load.

\subsection{Data Easily Imported into Other Tools}

A strong desire of the users at the water authorities was to be able to easily use the tools they use in their daily work for further analysis of data. Most important here was Excel and various GIS-tools. Therefore, an important principle for the design was that available data can easily be imported into other tools for further use and analysis. This has led to the decision to offer data about a specific geographic area in Excel format. The data is organized in sheets so that it is easy to read and understand as shown in the example in figure 2. However, it can also easily be further analyzed in Excel or by export to other tools by the end user. Data about the whole country is available as Excel sheets and as text files. These files can easily be imported in GIS tools together with the shape file for the polygons which is also provided on the site. 


\subsection{Transparency of Results}

During the meetings with the users we had many questions about the quality of the results and how they were computed. In particular this is important for a user which have access to more detailed information about a specific local area than is encoded in the input data for S-Hype. Therefore, it is important for the users to be able to assess the validity of the simulated data. On the site we have implemented this by making the model transparent in several ways: by explaining the S-Hype model; showing input data for the model and by a tool assessing the validity of results. All these features will be further explained in the following section.

\subsection{Agile Development That Allows Fast Changes}

The design has enabled easy access to the desired data by the end users. However, an as important issue is that it is also favorable for redesign and adding new features. From a technical perspective this has been provided in two ways. Firstly, the general design with a number of applications where each application has few dependencies to other parts of the site. This makes it easy to add a new application to the site without affecting any of the other applications. Secondly, the data representation where we use text files with data organized close to the model results achieved from S-Hype. This makes it very fast to publish a new release of the model and to add new features and results to the end users.

\section{Data Validity and Transparency}

During the discussions with end users an important issue was quality and uncertainty of the data provided by the model. The users are interested in comparing simulated results with older simulations and with local knowledge for their specific area. Whenever there are differences, it is important for the users to understand more about the simulated values to analyze the cause of these differences. To support them we decided that it was important to make the simulated data more transparent, i.e. to explain the underlying assumptions and setup of the model. To achieve transparency we have added three different kinds of features; a thorough reference guide explaining the S-HYPE model and how it was setup; input data for the model exposed on the site and finally an evaluation application which makes it possible to investigate the validity of the model from different perspectives.

The data used for model setup includes data on, for instance, land use, soils and point sources. As with result data from the simulations, the input data is provided for easy download on the site, for each subbasin as well as for the whole country. The data is collected directly from the model setup, but summarized in a way that makes it easier to understand for the end user that is not an expert on the model. Based on this data the users can easily asses the validity of the model set up compared to their local knowledge. The model setup builds on global databases (see the reference guide [1] for more information) and in some cases these do not match recent local changes. For the large scale, this has minor effect on the result of the simulation, but it might make 
a difference for a local area. Figure 2 shows an example of the provided input data for one subbasin. As shown in the figure, the data is provided as Excel, which makes it easy to read and further process. In the example we see input data on land use, soil and point sources.

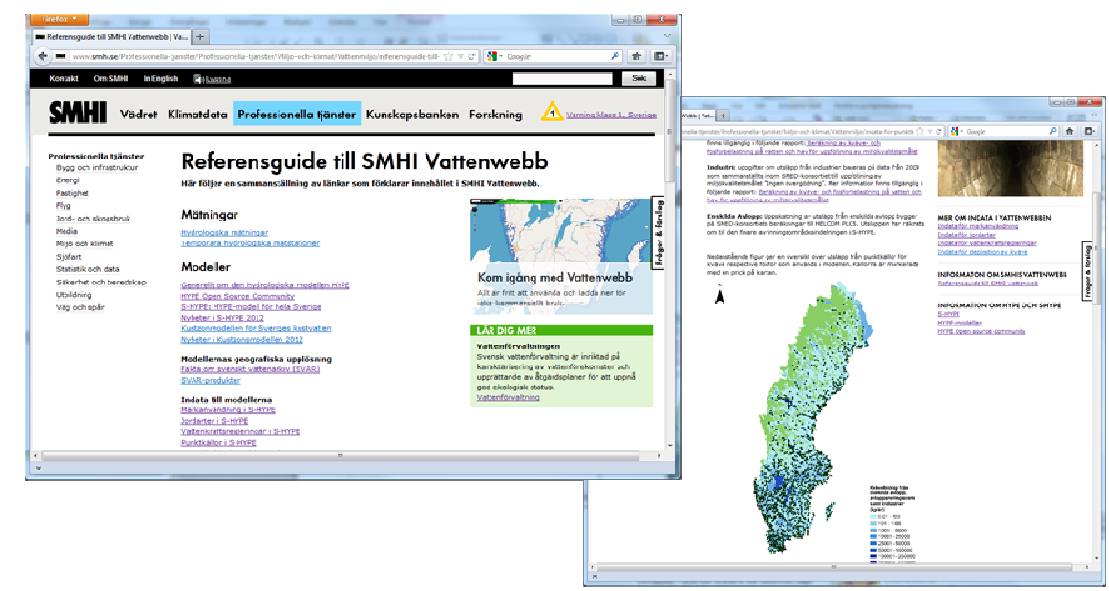

Fig. 3. Examples from the vattenweb.smhi.se reference guide. To the left we show the index page which is the entry point to the information. To the right we show one example describing information on point sources.

Publishing the model data made the users interested in where these data originate from and how they were used by the model. This raised a need for explaining how the model data was derived and we decided to provide a reference guide where origin of data as well as the processing or assimilation performed for the model setup is explained. This guide was provided as a set of web pages. Figure 3 shows the introduction page together with parts of the information available for soils. This allows users to understand the model assumptions and explain reasons for differences to more detailed information on local conditions they might have access to.

The features discussed above give the user ways to understand the model validity based on the model setup. However, there was also a need to present the quality of the results. To allow the end users to further evaluate quality, the site provides an interactive tool to compare the simulated results with measured values. Figure 4 shows a sample view of the tool. The tool presents model uncertainty in a map which gives an easy to understand overview of the model performance. The user can then select basins of his or her interest based on catchment size or geographic area, or make a detailed study of the validity of results for a particular catchment or group of catchments. The tool allows selection of which variable and size of catchment that are of interest, but also to zoom in to a specific geographic area. For each subbasin where measured data exist the user can inspect the measured time series and compare them to the simulated values. This gives valuable information about model performance for different geographic locations. 

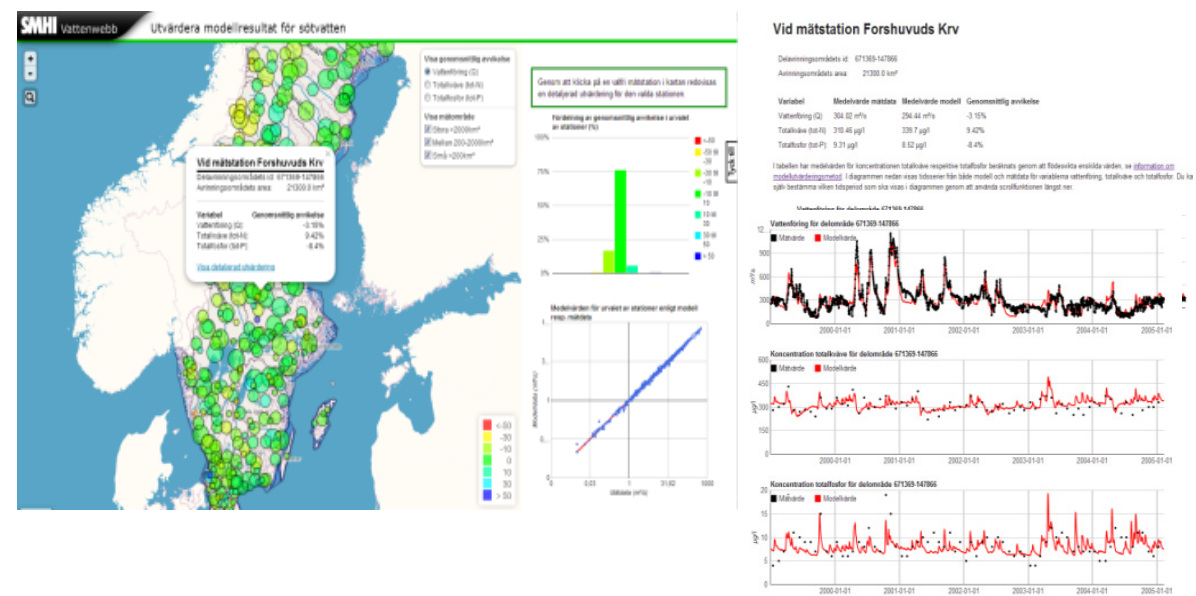

Fig. 4. This figure shows a sample view of the interactive evaluation tool. The map to the left gives an evaluation of the model performance compared to measured data. The user can select whether he is interested in discharge, nitrogen or phosphorous, it is also possible to focus on a specific size of basin or a geographical area by zooming in the map. To the left we show the more detailed information available for each station, where the user can compare details of modeled and measured time series.

\section{$5 \quad$ Related Work}

There are many available sites that present water related information. Several countries, such as Germany [7], United Kingdom [8], Belgium [9], Australia [10] and the United States [11] have publicly available water information services. These sites publish information on measurements and statistics. The Australian site is of particular interest since it publishes measurements and warnings together with data on water and water quality as yearly means. The American site [11] and the CUASHI service [12] are designed as portals where time series data is available for download. At the CUASHI site, time series is available in WaterML, together with a client program that can be downloaded by the user for further analysis of the data.

None of the above sites combines measured and modeled data in the same way as vattenweb.smhi.se site does. This means that they do not have to address the issues of transparency and validity of model data and how to make this information transparent for the end user. Such questions have been addresses by researchers working with water related environmental actions and how to involve stakeholders in the process. In this area there are a lot of interesting work in how to present water related information for stake holders and how to build tools that actively involve users in the decision process, e.g. [13], [14], [15]. These tools concentrate on a particular kind of problem and based on this problem try methods for decision support for this question.

The tools and methods used by these researchers are very interesting for us when developing vattenweb.smhi.se. However, as our site provide measurements and model data for a relatively general purpose, our focus is a bit different. For many problems 
addressed today within stakeholder research the focus is more on supporting the decision making process for a specific problem than providing simulated data and explanations for a more general use.

\section{Conclusion and Ongoing Work}

The new features for making the data more transparent have been appreciated by the end users and contributed to their understanding on how to use and interpret model results. The site is constantly getting new users and the user satisfaction is shown by many positive comments on the site. The users are very active in contributing with feedback for further development and new suggested features. During spring 2013 we have been working on further development of the website to allow interactive analysis of the impact of actions to improve water status. The interactive scenario tool is designed to support decisions on measures to reduce emissions from, e.g., industries, treatment plants and sewage systems. This is an important step towards the aim of using the site as a basis for planning actions to achieve an improved water status in Sweden. With current methods these kinds of assessments are done by changing input data to the model and then make a new simulation, which require high processing resources and result in long turnaround times for the end users. This old approach has made it hard to evaluate and compare a large number of combinations with possible actions, why a more interactive tool is very valuable for the end users.

Acknowledgments. The development of the S-Hype model and the web site has been funded by the Swedish water authorities. The development is also dependent on funding from Swedish Research Council (Vetenskapsrådet), The Swedish Environmental Protection Agency, The Swedish Research Council Formas and the European Commission, for model development and Scientific aspects. We are also grateful to our web team, in particular, Jens Gustafsson, Tomas Petersson and Anders Arstrand that has contributed largely to the features of the site.

\section{References}

1. SMHI Vattenwebb, http: / / www . vattenwebb.se

2. Arheimer, B., Dahné, J., Lindström, G., Marklund, L., Strömqvist, J.: Multi-variable evaluation of an integrated model system covering Sweden (S-HYPE). IAHS Publ. 345, $145-150$ (2011)

3. Arheimer, B., Lindström, G., Pers, C., Rosberg, J., Strömqvist, J.: Development and test of a new Swedish water quality model for small-scale and large-scale applications. XXV Nordic Hydrological Conference, Reykjavik, August 11-13, 2008. NHP Report No. 50, pp. 483-492 (2008)

4. Lindström, G., Pers, C.P., Rosberg, R., Strömqvist, J., Arheimer, B.: Development and test of the HYPE (Hydrological Predictions for the Environment) model - A water quality model for different spatial scales. Hydrology Research 41(3-4), 295-319 (2010) 
5. Strömqvist, J., Arheimer, B., Dahné, J., Donnelly, C., Lindström, G.: Water and nutrient predictions in ungauged basins - Set-up and evaluation of a model at the national scale. Hydrological Sciences Journal 57(2), 229-247 (2012)

6. Swedish water archive (SVAR), http://www.smhi.se/klimatdata/hydrologi/sjoar-ochvattendrag/ladda-ner-data-fran-svenskt-vattenarkiv-1.20127

7. Hochwasserportal Länder- Übergreifendes, http: / / www . hochwasserzentralen.de/

8. National river flood archive, Centre for Ecology \& hydrology, http: //www.ceh.ac.uk/data/nrfa/index.html

9. WEISS Planning support system, http://weiss.vmm.be/

10. Australian Government, Bureau of Meteorology, http: / /www. bom.gov. au/water/

11. USGS Water Resources for the United States, http: / /water.usgs.gov/

12. CUASHI HIS, http: / / his. cuahsi .org/

13. Brugnach, M., Dewulf, A., Henricksen, H.J., van der Keur, P.: More is not always better: Coping with ambiguity in natural resources management. Journal of Environmental Management 92(1), 78-84 (2011)

14. Carr, G., Loucks, D.P., Bloeschl, G.: An Analysis of Public Participation in the Lake Ontario - St. Lawrence River Study. In: Gover, V.I., Kratzenberg, G. (eds.) Water Comangement, ch. 4, CRC Press, Taylor and Francis Group, Boca Raton, USA (2013)

15. Jonsson, A.C., Andersson, L., Alkan Olsson, J., Jonsson, M.: Defining goals in participatory water management: merging local visions and expert judgements. Journal of Environmental Planning and Management 54(6) (2011), doi:10.1080/09640568.2010.541738 